3. HISTORIA DEL DERECHO ESPAÑOL 

Revista de Estudios Histórico-Jurídicos

[Sección Historia del Derecho Español]

XXXIV (Valparaíso, Chile, 2012)

[pp. 167 - 194]

\title{
EL MANDATO DE UNIFICACIÓN JURÍDICA Y \\ LA CONSTITUCIÓN ESPAÑOLA
}

\author{
[The Mandate of Juridical Unification and the Spanish Constitution]
}

\author{
Antón Lois Fernández Álvarez* \\ Universidad de Vigo, España
}

\begin{abstract}
RESUMEN
El presente trabajo analiza la influencia del ideal de unificación jurídica, como elemento clave del progreso jurídico de las revoluciones liberales, sobre los procesos de Constitucionalismo y, posteriormente, de Codificación civil, todo ello dentro del panorama jurídico español y del contexto histórico decimonónico. Asimismo trata de apoyar las teorías de que el proceso constitucional fue determinante en la codificación y de cómo ésta se retrasó más de medio siglo por la oposición de los movimientos antiuniformistas que defendían sus derechos forales.

Palabras clave

Codificación civil - Constitucionalismo - Derechos forales - Unificación jurídica.
\end{abstract}

\begin{abstract}
This work analyzes the influence of the ideal of legal unification, as a key element for the legal progress of the liberal revolutions, on the Constitutionalism processes and, subsequently, of the Codification of civil law within the Spanish juridical spectrum and the historical context of the $19^{\text {th }}$ Century. It is also an attempt to support the theories suggesting that the constitutional process was crucial for the codification and how this was delayed for more than half a century due to the opposition of antiuniformitarian movements that defended their rights as autonomies.-
\end{abstract}

KeYwords

Civil codification - Constitutionalism - Autonomy rights - Juridical Unification

ReCibido el 18 de enero y ACEPTADO el 7 de julio de 2012

* Profesor Doctor del Área de Ciencia Política y de la Administración de la Universidad de Vigo, España. Dirección postal, Facultad de Ciencia Política y de la Educación, Campus Universitario, 32004 Ourense, España. Correo electrónico, alfa@uvigo.es 


\section{Contexto COnSTitucional DECimonónico}

Tal y como desarrollaremos en este trabajo, la implantación constitucional fue un acontecimiento básico para entender el largo y abrupto proceso de codificación civil en la España del siglo XIX. Por ello, se hace imprescindible realizar una breve contextualización acerca de la formación del constitucionalismo español haciendo ya una parca referencia a esta influencia sobre la uniformización de la normativa civil.

Si bien la primera constitución no vio la luz hasta el año 1812, la historia del constitucionalismo español tiene su origen en el estatuto real de Bayona de 8 de julio de 1808 , cuya verdadera naturaleza no fue la de norma constitucional sino la de carta otorgada ${ }^{1}$. En este texto, José I de España ${ }^{2}$ adapta el modelo constitucional bonapartista y consagra determinados derechos para la ciudadanía, estableciendo, además, una monarquía hereditaria aunque limitada.

La importancia de este documento para el constitucionalismo español, aún teniendo una aplicación muy restringida en función de los acontecimientos bélicos que se vivieron durante el tiempo de su vigencia ${ }^{3}$, estriba en que sirvió de base a la reacción constitucional posterior, al tiempo que ciertos de sus elementos fueron incorporadas en la Constitución de Cádiz de 1812 al ser el primer texto legal con vigencia en España que incorpora algunos principios liberales en lo que podríamos considerar un liberalismo atenuado. Asimismo se ha destacado la influencia del estatuto de Bayona en diferentes textos constitucionales americanos, de manera que podemos afirmar que la implantación de regímenes constitucionales en toda la América hispana fue la respuesta, americana, al constitucionalismo inaugurado en Bayona y Cádiz, pero teniendo en cuenta que el estampido nació en Bayona, que se convirtió en reto y, en cierta manera, ejemplo a seguir ${ }^{4}$. Por lo que respecta a nuestro estudio, su repercusión es todavía mayor si tenemos en cuenta su propen-

\footnotetext{
${ }^{1}$ Ello supone, como es sabido, que se trata de un texto derivado del poder absoluto del monarca y no de la aprobación por parte de la soberanía popular. Aún así, en este caso, quiso salvarse, aunque sólo fuera de manera formal, este último aspecto de manera que, desde el punto de vista formal, sí fue aprobada por un grupo reducido de 65 diputados españoles, convocados en Francia, a quienes se les presentó un texto sin posibilidad de enmienda.

${ }^{2}$ José Bonaparte fue nombrado Rey de España el 7 de julio de 1808, mediante Decreto de su hermano, el emperador francés Napoleón I, una vez que éste consiguió, mediante una hábil estrategia, que los derechos de la corona española recayeran sobre sí mismo después de que, atrayéndolos a la localidad francesa fronteriza de Bayona, forzase a Carlos IV a abdicar en favor de su hijo Fernando VII y obligase a éste a cederle sus derechos dinásticos sobre la corona de España. El reinado de José I se extendió, oficialmente, hasta el 11 de diciembre de 1813.

${ }^{3}$ Dichos acontecimientos se refieren a la contienda de la Guerra de la Independencia española frente a la invasión francesa. Dicha sublevación comenzó el 2 de mayo de 1808, días antes, incluso, a que se nombrara el rey extranjero, y terminó con la restauración del monarca español Fernando VII el 11 de diciembre de 1813. Las circunstancias de este período histórico resultaron decisivos para la independencia de muchas colonias españolas en Sudamérica.

${ }^{4}$ Martiré, E., La importancia institucional de la Constitución de Bayona en el constitucionalismo hispanoamericano, en Historia Constitucional (revista electrónica), 9 (2008). Manifiesta este autor (p. 5) que, no escapó a su influjo ni la Constitución de 1812, ni la portuguesa del año 22, ni el torrente de constituciones americanas que brotaron en Iberoamérica sucesivamente.
} 
sión o vocación codificadora, derivada de su vocación bonapartista. Así, el texto preveía la consagración de "un solo Código de Leyes Civiles y Criminales" (artículo 96), y “un solo Código de Comercio para España e Indias” (artículo 113)5.

A partir de este momento y, sobre todo, de la aprobación de la Constitución de 1812, la historia del constitucionalismo español decimonónico, coincidente diacrónico con los sucesivos intentos y logros de la codificación civil, finalizada en 1889 con la aprobación del Código Civil, se desgrana, además de los citados, a través de los textos constitucionales de $1837,1845,1869$ y 1876, a los que podemos unir, por su alcance, los del Estatuto Real de 1834, la Constitución non nata de 1856 y el proyecto constitucional de $1873^{6}$.

La Constitución de $1812^{7}$ tuvo una agitada vigencia, notoriamente menor que su influencia posterior, y que se extendió en tres períodos, de 1812 a 1814 , de 1820 a 1823 y durante un breve periodo en 1836 . De sesgo marcadamente liberal, recogiendo por primera vez la soberanía nacional y el principio de separación de poderes, además de una nutrida lista de derechos individuales, fue discutida y aprobada en la España ocupada por los franceses por las Cortes españolas acantonadas en Cádiz. Derogada por el monarca Fernando VII en 1814, éste fue conminado a aceptarla tras el pronunciamiento liberal del general Riego en 1820 y nuevamente derogada una vez fracasado dicho movimiento en $1823^{8}$. Finalmente, tuvo otra corta vigencia entre 1836 y la aprobación del texto constitucional de $1837^{\circ}$. En

${ }^{5}$ El paralelismo de nuestra Constitución de 1812 es claro en relación a la Carta o Constitución de Bayona de 1808

${ }^{6}$ Siguiendo a GONZÁlez-Ares, J. A., Introducción al estudio del constitucionalismo español. 1808-1975 (4a edición, Santiago de Compostela, 2003); y a DE EsTEBAN, J. - GonZÁlezTrevijano, P. J., Curso de Derecho Constitucional español (Madrid, 1994), podemos establecer como rasgos internos característicos del constitucionalismo español, de un lado, la falta de originalidad de los textos constitucionales, reflejada tanto en su espíritu como en su articulado, y con notable influencia de la cultura política de Francia que ha marcado de forma indeleble el inicio y desarrollo del Derecho Constitucional español; y, de otro lado, la excesiva vinculación ideológica y partidista de las constituciones en una plasmación de la confrontación dialéctica de lo que dio en llamarse las dos Españas contrapuestas.

${ }^{7}$ También conocida como “Constitución de Cádiz”, o "de las Cortes de Cádiz” o, vulgarmente, como "la Pepa, por haber sido aprobada el 19 de marzo, día de San José. Esta denominación ordinaria, otorgada por el pueblo, tuvo una curiosa pero cierta repercusión, y es que siendo habitual que todas las normas jurídicas de la España democrática se publiquen en el Boletín Oficial del Estado al día siguiente de la sanción y promulgación real, la actual Constitución se publicó el 29 de diciembre de 1978, dos días después de su sanción, para evitar que tal publicación coincidiese con el 28 de diciembre, día de los Santos Inocentes, y con ello soslayar las posibles bromas o denominaciones populares sobre la norma suprema. Esta anécdota ha sido extraída de una conversación personal con D. Gregorio Peces-Barba, miembro de la Comisión constitucional que redactó la Constitución española vigente en la actualidad.

${ }^{8}$ En el juramento de la Constitución de Cádiz por Fernando VII de España de 10 de marzo de 1812, recogido en el Manifiesto del rey a la Nación española se incluía la famosa sentencia monárquica de "marchemos francamente, y yo el primero, por la senda constitucional'. Una franqueza que, a la postre, habría de durar menos de tres años. Sobre la rehabilitación de la Constitución durante el trienio liberal véase: VARELA SuANZES-CARPEgna, La monarquía imposible, la Constitución de Cádiz durante el trienio, en AHDE., 66 (1996).

${ }^{9}$ ATARD, E., El constitucionalismo español, 1808-1987. Ensayo histórico-jurídico (Valencia, 
lo que atañe a nuestro estudio, la carta gaditana preceptuaba que los Códigos civil, criminal y de comercio habrían de ser unos mismos para toda la Monarquía (artículo 258). El paralelismo en este particular de la Constitución de 1812 es claro en relación a la carta de Bayona de 1808 y sus citados artículos 96 y $113^{10}$.

De esta manera se introducía de manera oficial la codificación en España ${ }^{11}$.

El siguiente texto, el Estatuto Real de $1834^{12}$, tuvo una breve y poco destacada validez durante la regencia de la reina María Cristina, viuda de Fernando VII, hasta la rehabilitación de la Constitución de Cádiz en 1836 que desembocaría finalmente en la Constitución de $1837^{13}$. Esta norma fue producto del acuerdo entre el partido progresista y el moderado y vino a significar una revisión del texto de 1812 . De esta manera se validó una norma que respetaba la soberanía nacional y la separación de poderes, pero que enfatizaba la remisión constante a las leyes ordinarias para regular instituciones y derechos lo cual, en la práctica, supone un importante vaciado de los poderes de la Constitución (de aquí el hecho de que se trate de un texto breve de tan sólo 77 artículos). Destaca, asimismo, una notable influencia de las Constituciones francesa de 1830 y belga de $1831^{14}$.

La Constitución de 1845 es el corolario de los acontecimientos que derivaron en la llamada "década moderada" (1844-1854) y la plasmación de los principios de esta ideología junto a los intereses puramente monárquicos. Se elabora, así, un texto que consagra la soberanía compartida entre la Corona y las Cortes, la práctica desaparición de la división de poderes, la restricción de las libertades y la confesionalidad del Estado ${ }^{15}$. El fin de esta década moderada trajo consigo la discusión y elaboración de la Constitución de 1856, denominada non nata, ya que a pesar de ser aprobada por las Cortes constituyentes no llegó a estar vigente al

1988); Cano Bueno, Materiales para el estudio de la Constitución de 1812 (Madrid, 1989); SeVIlla Andrés, Historia política de España (1800-1973) (Madrid, 1974); TOMÁs Villarroya, Las reformas de la Constitución de 1812 en 1836, en Revista del Instituto de Ciencias Sociales, 4 (1964).

${ }^{10}$ Así lo resalta también Tomás y Valiente, Obras completas (Madrid, 1997), p. 1420.

${ }^{11}$ Baró Pazos, La codificación del Derecho civil en España (1808-1889) (Santander, 1993), p. 53.

${ }^{12}$ El valor constitucional del Estatuto Real de 1834 resulta más que dudoso y ha sido generalmente cuestionado. No en vano toda su naturaleza jurídica resulta tan incierta y desconcertante que TOMÁs Y VALIENTE, Obras, cit. (n. 10), acabó por calificar el texto como "carta otorgada” en su origen, "ley de cortes" por su temática, "ley restauradora” de las antiguas Leyes del Reino por su apariencia y "símbolo del moderantismo" español por su contenido ideológico.

${ }^{13}$ Sobre este particular véase: TOMÁs Villarroya, El sistema político del Estatuto Real (Madrid, 1968).

${ }^{14}$ Véase: GonZÁleZ-Ares, J. A., Introducción al estudio del constitucionalismo español, cit. (n. 6); Tomás y VAliente, Notas para una nueva historia del constitucionalismo español, en Sistema, 17-18 (1977); Códigos y Constituciones (1808-1978) (Madrid, 1989); y Obras, cit. (n. 10); TORRES Del Moral, Constitucionalismo histórico español (Madrid, 1986); Varela SuAnZes-CarPegna, La constitución española de 1837, una Constitución transaccional, en Revista de Derecho Politico, 20 (1983-1984).

${ }^{15}$ Véase: CÁNOVAS SÁNCHEZ, El moderantismo y la Constitución española de 1845 (Madrid, 1985); GONZÁLEZ-ARES, La Constitución moderada de 1845, notas y comentarios en el ciento cincuenta aniversario de su promulgación, en Revista del Colegio de Abogados de Ourense, 21 (1995). 
no ser sancionada por la reina ${ }^{16}$. Un brusco cambio en la presidencia de gobierno motivó la reposición de la norma de 1845 si bien el esfuerzo constituyente sirvió de base a la Ley constitucional de Reforma de 1857 que atenuó considerablemente los principios antiliberales de la Constitución moderada.

De esta forma la Constitución de 1845 estuvo vigente hasta el estallido revolucionario de 1868 , el cual inicia un breve pero intenso período que culminará con la proclamación de la Primera República (1873-1874) y que se conocerá como el "sexenio democrático". Fruto de este tiempo fue la Constitución de 1869, una norma que, al conjugar los principios liberales clásicos con el principio democrático básico del sufragio universal, se convierte en la "primera Constitución democrática de nuestra historia” precediendo en varias décadas a conquistas semejantes en otros países ${ }^{17}$. Además de ello, nuevamente se incide en el ideal codificador propio del liberalismo con la inclusión constitucional de la "unidad de legislación y de fueros"18.

Después de la acelerada experiencia republicana que en menos de un año vio pasar a cuatro presidentes de gobierno, un proyecto de constitución federal en 1873, que reformaba la anterior incidiendo en el federalismo republicano, en la descentralización política y administrativa y en el laicismo estatal ${ }^{19}$, y un gobierno republicano unitario de sesgo dictatorial, se fue allanando el camino hacia la restauración monárquica de la dinastía borbónica en 1874 . En menos de dos años se aprobó una nueva Constitución, la de 1876, que se convirtió en causa y consecuencia del bipartidismo restauracionista. Ello vino a suponer que dos facciones políticas de tendencias centristas ${ }^{20}$ se turnaron en el ejercicio de un gobierno bajo los preceptos de soberanía compartida y de colaboración de poderes, que reaccionaba frente al consabido principio de separación de los mismos. En la práctica, el sistema constitucional establecido sentó las bases para el reforzamiento de los poderes oligárquicos y caciquiles, lo cual se antojaba un importante escollo para el centralismo político y la unificación codificadora. En todo caso, el equilibrio político proporcionado por el bipartidismo y la flexibilidad otorgada a la carta

${ }^{16}$ Casanova Aguilar, Aproximación a la Constitución nonnata de 1856. Presentación general y primera publicación del texto integro (Murcia, 1995).

${ }^{17}$ En palabras del ponente constitucional Solé Turá, en Solé TurÁ, J. - AJA, E., Constituciones y periodos constituyentes en España (15a edición, Madrid, 1990). Véase también: Clavero, B., Evolución histórica del Constitucionalismo español (Madrid, 1984); EL MISMO, Materiales primeros para una historia constitucional de España, en AHDE., 59 (1989).

${ }^{18}$ Donezar, J. M., La constitución de 1869 y la revolución burguesa (Madrid, 1985); GoNZÁlez RodrígueZ, La forma de gobierno en el debate constituyente de 1869, en Revista de Derecho Politico, 55-56 (2002).

${ }^{19}$ De todas formas el proyecto no era marcadamente federal sino que realmente lo que hacía era adoptar criterios que desde el punto de vista jurídico-político podían considerarse como de autonomía regional, según TORRES DEL MORAL, Constitucionalismo histórico español, cit. (n. 14). Véase también: Vallejo, J., Orden, libertad, justicia. Figuración constitucional republicana (1873), en $A H D E ., 57$ (1997).

${ }^{20}$ El Partido Conservador Liberal de Cánovas del Castillo y el Partido Liberal Constitucional de Sagasta. 
magna de 1876 la convirtieron en el texto más duradero de la historia constitucional española hasta el momento (de 1876 a 1923 y de 1930 a 1931$)^{21}$.

Culminada la codificación civil española con la aprobación del Código Civil en 1889 , durante la vigencia de la norma constitucional de 1876, la historia del constitucionalismo español del siglo XX se resume en dos textos constitucionales 1931 y 1978, separados por el conocido período del gobierno de Franco.

\section{CODIFICACIÓN CIVIL Y UNIFICACIÓN JURÍDICA}

La codificación es uno de los fenómenos de contenido cultural, político y jurídico de mayor trascendencia de la sociedad contemporánea. Supone un paso destacado dentro de la evolución del Derecho y desde el punto de vista histórico contribuyó decisivamente a un cambio de era en la humanidad derribando el sustento y estructura estatal del Antiguo Régimen. Ello supone que los procesos de codificación son, sin duda, uno de los acontecimientos históricos más complejos de la evolución jurídica puesto que tal situación comporta un culmen de madurez en la ordenación del Derecho, que presupone la concurrencia de diferentes y dilatadas circunstancias, como siglos de variedad legislativa, dispersión normativa, desorden en la aplicación de las normas, tensiones entre corrientes filosóficas y filosófico-jurídicas, servicio a marcadas ideologías políticas y pugnas doctrinales, elementos que, en algunos momentos, se ven reflejados con gran crudeza ${ }^{22}$.

Desde la óptica del pensamiento jurídico liberal, cuyo estrato filosófico reinventa modelos jurídicos de siglos de antigüedad, un código es "una ley de contenido homogéneo por razón de la materia, que de forma sistemática y articulada, expresada en un lenguaje preciso, regula todos los problemas de la materia unitariamente acotada" 23 . Pero un código se refiere, además, a una obra que aspira a la globalización jurídica en un determinado territorio, en definitiva, a la plenitud. En el fondo podría decirse que la aspiración a la plenitud es funcional al deseo del código de imponerse, de dominar, de considerarse jurídico. El código, históricamente, ha sido llamado a realizar la función unificadora, que se nos aparece como el corolario de la aspiración a la plenitud ${ }^{24}$.

Así las cosas podemos colegir, pues, que toda codificación precisa de un prurito

${ }^{21}$ García Canales, Reforma de la Constitución de 1876, en Revista de Derecho Politico, 8 (1981); Pérez-Prendes, Continuidad y discontinuidad de la Constitución de 1876, en Revista de Derecho Político, 8 (1981); SÁNCHEZ FERRIZ, La Restauración y su constitución política (Valencia, 1984).

${ }^{22}$ Alonso Pérez, Ideal codificador, mentalidad bucólica y orden burgués en el Código civil de 1889, en Centenario del Código Civil (Madrid, 1990), I, p. 17.

${ }^{23}$ Tomás y Valiente, Obras, cit. (n. 10), p. 1399.

${ }^{24}$ Codificar, como su nombre indica, es la obra científica realizada por un mismo legislador, ordenando en forma sistemática todas las disposiciones que deben regular un materia jurídica, Lasso Gaite, Crónica de la Codificación española, IV: Codificación civil (Génesis e historia del Código) (Madrid, 1979), p. 11, y teniendo en cuenta las leyes anteriores, los hábitos y costumbres del país para el que legisla, con reglas breves y precisas. Cuidando con esmerado afán de la unidad de la obra, de su simetría y del buen orden de todas sus materias, Arrazola, L., Enciclopedia Española de Derecho y Administración (Madrid, 1856), IX, p. 252. 
unificador. Ahora bien, conviene preguntarse si la labor codificadora, que se consideró imprescindible en un momento dado para el tráfico y la seguridad jurídica, no se sirvió de los procesos unificadores para ser aceptada o si, al contrario, los movimientos políticos de unificación del poder utilizaron la codificación jurídica para establecerse en un determinado momento histórico en el que las circunstancias políticas, económicas y sociales exigían un agotamiento de la dispersión del poder. En definitiva, se trata de indagar por qué motivo esta unificación territorial ha sido tan intensamente deseada y solamente impuesta en ocasiones muy contadas. No se excluye que se deba hablar de una convergencia de intereses y, mejor todavía, de una eficaz consonancia de proyecto político y un programa económico en cuya base se articulaba la unificación jurídica ${ }^{25}$. Las experiencias de unificación política europea de la centuria decimonónica nos ilustran claramente acerca del hecho de que, conforme a los intereses crematísticos, la unificación del derecho privado se presentaba como última medida que había que llevar a efecto para que el territorio nacional -ya unificado a nivel económico con la abolición de las aduanas internas y con la proclamación de principios constitucionales que sancionaba la movilidad de las personas y de las mercancías- pudiese finalmente comenzar a funcionar como mercado. Ello queda corroborado por el hecho de que la codificación mercantil -que perseguía la uniformidad de las transacciones comerciales- se anticipe en más de medio siglo a la civil ${ }^{26}$.

Las dificultades para lograr la unificación jurídica que toda codificación, como expresión de una soberanía nacional planteaba, radicaba precisamente en armonizar los derechos de los antiguos reinos con el derecho castellano. De esta manera se fija realmente el problema. La unificación jurídica se pretende a través de la construcción de un derecho racional que se quiere plasmar en un código válido para toda la nación; frente a esta pretensión se alzan los deseos de conservar los derechos históricos de los diversos reinos: se enfrentan así las que se denominan escuela filosófica y escuela histórica, tal y como trataremos en el último apartado de este trabajo. Por debajo de este aparente enfrentamiento entre dos escuelas diferentes se encierra, sin embargo, un planteamiento más radical, que consistía simplemente en lograr la unificación a través de una depuración racional del derecho castellano, el antiguo derecho real que pasará así a configurarse como derecho nacional, a partir de la idea de haber construido Castilla a España y la oposición por parte de los antiguos reinos a esta concepción, al contemplar España como una realidad surgida de la colaboración, al participar todos en un mismo plano de igualdad en su creación, de todos aquellos que se confirman en su conciencia como españoles. Se enfrentaban así dos formas distintas de concebir la articulación de los diferentes pueblos dentro del Estado español, como una expresión gráfica de una lucha por el poder $^{27}$.

${ }^{25}$ CARONI, Pio, Lecciones catalanas sobre la codificación (Madrid, 1996), p. 26.

${ }^{26}$ Rodríguez EnNes, Historia do Dereito de Galicia (Vigo, 2000), p. 150.

${ }^{27}$ Rodríguez EnNes, Proceso histórico de formación del Derecho civil de Galicia, en Dereito. Revista Xurídica da Universidade de Santiago de Compostela, 5 (1996), p. 275. Según decir de Gómez Arboleya, Estudios de teoría de la sociedad y del Estado (Madrid, 1962), pp. 451 y ss., el código tiene desde la Ilustración, una doble dimensión. Por su contenido, en cuanto que 
Cuando penetró con fuerza el ideal codificador, inoculado en el napoleónico texto del estatuto real 1808 y reivindicado expresamente en la Constitución liberal de 1812, España se encontraba jurídica y políticamente poco predispuesta, sin haber pasado por las transformaciones vividas por otros países de la Europa continental que conformaban asientos ideológicos o sociales de sus respectivos procesos codificadores. España es un país que no vivió la reforma protestante que exterminó inquisitoriamente un naciente y ortodoxo erasmismo; que atravesó con más amargura que triunfos un siglo de claroscuros, el barroco del siglo XVII, lleno de glorias literarias y artísticas, pero así mismo repleto de derrotas militares y miseria cotidiana; un país que entró en la centuria de la Ilustración europea con escasas energías intelectuales, carente de raíces propias desde las cuales orientarse en tiempos de reformas y revoluciones y sin ser capaz apenas de romper su ignorante aislamiento respecto a lo que fuera de sus fronteras se hacía y decía, se pensaba y se escribía. Por eso, mientras otros países comenzaron a publicar sus nuevos códigos ya en tiempos de las monarquías del despotismo ilustrado, España, yacía pasiva en profundo y mortífero letargo y su Derecho, construido en gran parte con materiales viejos e inservibles, permanecía confusamente recopilado ${ }^{28}$ y ajeno tanto a reformas legislativas ambiciosas, como a los nuevos aires doctrinales, unas y otros derivados del iusnaturalismo racionalista, desconocido por nuestros juristas y legisladores, salvo en sus más triviales subproductos ${ }^{29}$.

Así las cosas, la codificación se inicio entre nosotros partiendo de la más completa desorientación, lo que propició, en determinadas ocasiones, un mimetismo escasamente selectivo y, en otras, lentitudes y retrocesos nada beneficiosos para

el derecho codificado es fruto de una unión natural que es el patrimonio común de todos los hombres, el Código tiene vocación universal y acrónica. Pero el ámbito de su vigencia viene deslindado por el espacio hasta donde alcanza el poder político que ha de proponerlo; el código es así consustancial con un Estado nacional hasta el punto de erigirse en instrumento poderoso para contribuir a la construcción o al fortalecimiento de la unidad nacional en cuanto permitiese superar el particularismo jurídico y los sustituye por un sistema normativo unitario y coherente [cfr. TARello, G., Storia della cultura giuridica moderna, I: Assolutismo e codificazione del diritto (Bolonia, 1976), pp. 28-34].

${ }^{28}$ Las recopilaciones están muy lejos de crear un Cuerpo legal con carácter de verdadero Código. Se agrupan leyes sin orden, ni sistema, ni especialización de materias; falta un sentido íntimo de validez jurídica estable. Son colecciones de leyes o instituciones carentes de proporcionalidad en las que no existe una impronta nacionalidad de contornos inconfundibles [Cfr. Alonso Pérez, Ideal codificador, mentalidad bucólica y orden burgués en el Código civil de 1889, cit. (n. 22), p. 18]. La Novísima Recopilación, pese a promulgarse en los comienzos del gran siglo codificador, no estuvo a la altura de su tiempo, reiterando el tradicional sistema recopilador cuando ya se había publicado en Francia, con arreglo a modernos principios, el Código civil napoleónico. No extraña, por tanto, que MarTínez Marina, Juicio crítico de la Novísima recopilación (Madrid, 1820), la calificase de vasta mole levantada de escombros y ruinas antiguas; edificio monstruoso, compuesto de partes heterogéneas y órdenes inconciliables; hacinamiento de leyes antiguas y modernas.

${ }^{29}$ Clavero, B., La idea de Código en la Ilustración jurídica, en Historia, Instituciones, Documentos, 6 (Sevilla, 1979), pp. 49-88. 
la reforma legislativa que algunos procuraban ${ }^{30}$. No en vano se ha señalado que la codificación civil española fue la "larga historia de una frustración"31.

Sin duda fue una larga marcha, un proceso que parecía no llegar a su fin. Una sociedad burguesa con constitución, pero sin código civil era una sociedad incompleta, coja, mal construida. El mismo autor ha declarado que el código civil no se hizo antes "porque cuando se quiso no se supo y cuando se supo no se quiso" 32 . A diferencia de lo sucedido en Francia, donde el Code Civil precedió a los demás, el código civil no sólo no abrió en España el proceso codificador, sino que constituyó su último capítulo. Resulta paradigmático que aquí llegara a codificarse antes el Derecho procesal civil que sustantivo al que aquél debiera adaptarse. Retraso todavía más grave aún si tenemos en cuenta que nuestros ilustrados sintieron vivamente el ideal codificador desde el siglo XVIII ${ }^{33}$. Tal anomalía ha sido explicada por varias causas. Entre ellas destaca el hecho de no haber alcanzado y consolidado los principios sobre los que se apoya la revolución liberal -el derecho de propiedad y las libertades fundamentales de la persona- ${ }^{34}$.

Además de diferentes eventualidades políticas e históricas que, sin duda, influyeron en la dilación codificadora, pero que correspondería analizar en un estudio aparte, el otro factor determinante del fracaso de los sucesivos proyectos del código civil enlaza directamente con el objeto de este trabajo. Éste no fue otro que el hecho de que se inspiraban claramente en el designio de unificar, con la promulgación del código, el Derecho civil español y, por tanto, atacaba directamente a los derechos históricos de diferentes territorios peninsulares. Intento uniformista que, con reiteración, consiguieron frustrar las corrientes jurídicas y políticas que predominaban en aquellas regiones españolas que tenían un Derecho civil propio, y que pusieron todo su empeño en evitar la unificación del Derecho civil español; pues era claro que tal unificación se produciría, esencialmente, mediante extender el derecho civil castellano a todo el territorio español ${ }^{35}$. Los orígenes del denominado "problema foral" se sitúan a principios del siglo XIX ${ }^{36}$,

${ }^{30}$ Rodríguez Ennes, Historia do Dereito de Galicia, cit. (n. 26), p. 151.

${ }^{31}$ Tomás y Valiente, Obras, cit. (n. 10), p. 1475.

${ }^{32}$ Tomás y Valiente, Códigos y constituciones, cit. (n. 14), p. 26.

${ }^{33}$ En este sentido de Castro, F., Derecho civil de España (Madrid, 1955), I, p. 194, escribe, El ideal codificador se hará sentir especialmente en la España del siglo XVIII; está en los proyectos de Ensenada, en el antirromanismo de Macanaz, en la petición de leyes derivadas de principios racionales de Jovellanos y en todo el deseo reformista del Setecientos [

${ }^{34}$ Véase el interesante trabajo de MALUQUer DE MOTES, La codificación civil en España, sintesis de un proceso, en RDP. (1981), destinado a probar que la Codificación es el resultado final de un largo proceso, que no podría cerrarse hasta haber obtenido la total transformación de la propiedad y haber alcanzado el conjunto de los derechos individuales.

${ }^{35}$ Puig Ferriol, El denominado problema foral desde la perspectiva de un Centenario, en Centenario del Código civil (Madrid, 1990), I, p. 1617.

${ }^{36}$ Para Meléndez Valdés, Discurso de instalación y apertura de la Real Audiencia de Extremadura, en Discursos forenses (edición de M. J. Quintana, Madrid, 1821), p. 229 ss., según su propia experiencia jurídica, los fueros entre otros privilegios y excepciones, obstaculizan el elemental programa codificador, implicando que en el Derecho haya todo menos unidad y sistema. En la misma línea se manifestó CAmBronero, Discurso sobre la necesidad de una nueva Legislación para las provincias españolas y medios de formarla (Madrid, 1810), pp. 5 ss., para quien el Código 
y obedecen a unos condicionamientos de carácter político, que influirán sobre la futura estructuración del Derecho civil en nuestro país. En efecto, es también muy conocido que la unificación política española se realiza respetando fundamentalmente las instituciones - tanto públicas como privadas- de los distintos reinos que se habían instaurado en la península a raíz de la denominada Reconquista. En este sentido indica Piano-Mortari ${ }^{37}$ que, ni siquiera con el paso a la Edad Moderna, se eliminaron del todo las instituciones características de la particularización (o particularismo) medieval. Hasta el momento de la Revolución Francesa se observa en Europa la persistencia de organismos provinciales, autónomos, municipales y feudales y, por tanto, la pervivencia, junto a la legislación emanada del poder central del Estado, de los Derechos locales, reflejo organizativo de esta legislación de carácter particularizado, todavía no desaparecida y cada vez más anacrónica. Por tanto, no puede resultar asombros que semejante régimen jurídico se encontrase en contradicción con las exigencias y los ideales políticos de los Estados absolutos de la Edad Moderna.

Pero esta configuración política, por lo que hace a España, entra en crisis con ocasión de las guerras civiles carlistas, que llevan a instaurar un modelo de Estado uniformista, y a extender el ordenamiento jurídico que regía en los territorios, opuesto a los designios unificadores de la nueva monarquía triunfante. No deja de ser sintomático que sea también al final de la Primera Guerra Carlista que Navarra y el País Vasco pierdan su potestad legislativa en materia de derecho privado, a tenor de lo dispuesto en las Leyes de 25 de octubre de 1839 y 16 de noviembre de $1841^{38}$.

La subsistencia de los ordenamientos territoriales o regionales se cuestionará, cuando empiece a tomar cuerpo la idea de codificar el Derecho español. La codificación se inspiraba en los postulados de la escuela racionalista del Derecho natural y en los principios de la Ilustración y se tomará como punto partida para la formación del Estado moderno que había de instaurarse en nuestro país tras la Guerra de la Independencia. La ideología liberal de la época hará suyos estos postulados, que llevarán a propugnar la creación de un Estado centralista, en el

Napoleón ha superado a todas las obras de su clase desde los primeros esfuerzos de los hombres. Y frente a tal ideal del código francés, puede aquí contrastar todavía la realidad de los fueros españoles con su caos de cien códigos o pluralidad de códigos que equivale a no tener código alguno; contrasta el caos tenebroso de nuestro actual estado de justicia, si es que puede llamarse sistema un edificio de tantos órdenes... en cada uno de los cuatro reynos aragoneses, fueros diferentes en las tres provincias vascongadas, etc. por lo común, además cargados de reglas de feudalidad y complementados por un derecho romano anacrónico y por el derecho canónico, mezcla extravagante de derecho feudal y romano. Frente a todo ello, acabando justamente con toda esta historia el código político - se refiere a la Constitución de Bayona de 1808- debiera complementarse con la promulgación en España del Código francés, único medio de depurar nuestro sistema de legislación.

${ }^{37}$ Piano-Mortari, s. v. Codice. Premessa storica, en ED., VII, p. 229.

${ }^{38}$ En efecto, según el artículo 1 de la Ley de 1839 se confirman los Fueros de las Provincias Vascongadas y Navarra, sin prejuicio de la unidad constitucional de la Monarquía; pues la conservación de los tradicionales Fueros comportaba la supresión de las instituciones más representativas de las referidas provincias. Orientación ésta que sigue la posterior Ley de 16 de Noviembre de 1841, que privó a Navarra de sus órganos de producción legislativa. 
cual la unidad legislativa se pondrá al servicio de la unidad política. Pero los principios políticos del liberalismo no son unánimemente aceptados por la sociedad española del siglo pasado, y este hecho influirá decisivamente en el proceso de la diversidad legislativa española en materia de Derecho civil ${ }^{39}$.

\section{ETAPAS DE LA CODIFICACIÓN CIVIL ESPAÑOLA}

En cuanto al análisis cronológico de los ítems que configuraron el proceso de la codificación civil española, si seguimos la división periódica de la codificación española propuesta por autores como Baró o Tomás y Valiente, se aprecia nítidamente que dicha estratificación se ve condicionada por el discurso de la historia constitucional ${ }^{40}$.

La primera etapa corresponde a los prolegómenos de la codificación y se extiende de 1808 a 1843 . En ese espacio temporal encontramos las referencias del estatuto de Bayona, la Constitución de Cádiz y la Constitución de 1837, todas ellas con explícitas referencias a la uniformidad legislativa. Durante la segunda vigencia del texto gaditano se redacta el primer Proyecto de Código Civil de 1821.

La segunda etapa de oficialización de la codificación (1843-1854) coincide, prácticamente, con la década moderada y la Constitución de 1845, si bien tiene su inicio en la creación de la Comisión General de Codificación mediante Decreto de 19 de agosto de 1843. Esta Comisión y el impulso constitucional dieron pie al Proyecto de Código Civil de 1851 ("Proyecto García Goyena") que servirá, a la postre, de fuente principal en la redacción del código definitivo de 1889.

La siguiente es la etapa intermedia de la codificación (1854-1875) marcada por la ausencia de acuerdo para la consecución de la unificación de la legislación civil, lo que provoca la aprobación de distintas leyes especiales que paulatinamente irán alcanzando la pretendida uniformidad jurídica de los ciudadanos. Tomás y Valiente concede, dentro de este periodo una cuarta etapa que iría desde 1868 hasta 1874 , en función de la revolución social y jurídica que supuso el sexenio democrático ${ }^{41}$.

Finalmente la etapa de culminación de la labor codificadora (1875-1889) concuerda con la Restauración monárquica, la Constitución de 1876 y la finalización del proceso codificador con la aprobación del Código Civil de 1889.

Respecto de la primera etapa destaca, como se ha dicho, el Proyecto de Código Civil de 1821, como primera muestra o intento de codificación civil de nuestro país. El código en ciernes, impulsado por el protagonismo del diputado Nicolás María Garelly, pretendía desarrollarse en torno a dos directrices básicas. La primera

\footnotetext{
${ }^{39}$ Véase al respecto: RocA TRÍAs, El Código civily los derecho nacionales, en especial el Derecho civil catalán, en RJC., 3 (1997), pp. 7-59.

${ }^{40}$ Baró Pazos, Codificación, cit. (n. 11), pp. 17 ss.; Tomás y Valiente, Obras, cit. (n. 10), pp. 1418 ss.

${ }^{41}$ Para Baró Pazos, Codificación, cit. (n. 11), p. 19, a pesar de que dentro de este lapso histórico se produjo un acontecimiento de especial relevancia como fue la revolución de 1868 y la aprobación de la Constitución de 1869, los expresos y novedosos derechos individuales que recogía su articulado no tuvieron significación para la Codificación civil hasta el siguiente período.
} 
de ellas, de corte procedimental, significó que los diputados en Cortes del trienio liberal pretendieron redactar un texto uniformizador a través de una comisión formada exclusivamente por diputados, sin dar entrada a juristas o especialistas ajenos a las Cortes. La segunda orientación consistía en la amplitud de la idea de código sustentada por los impulsores, de hecho que se pretendía recopilar y sistematizar no sólo las materias básicas del Derecho privado, sino otras relativas a cuestiones procedimentales e incluso elementos propios del Derecho administrativo. Movidos por el ímpetu codificador liberal, los diputados traspasaron incluso el mandato constitucional de 1812 que se ceñía a la ordenación de los códigos civil, criminal y de comercio ${ }^{42}$. De estas intenciones salió un texto de casi 500 artículos, correspondientes al título preliminar y a los dos primeros libros, precedido incluso por un discurso reivindicador de la tradición jurídica nacional. El proyecto de 1821 resulta, en opinión de Escudero, un trabajo notable ${ }^{43}$, o más aún "el intento legislativo más curioso y original de nuestros tiempos modernos" ${ }^{44}$. No en vano su interés, a pesar de no haber sido concluido, radica en la muestra de la preocupación social por la llegada de la codificación y de haber servido de estímulo para el inicio de la labor codificadora en nuestro país.

En esta primera etapa, que hemos denominado de prolegómenos de la codificación, se encuentran recogidos, asimismo, dos nuevos intentos codificadores, como son el Proyecto de Código Civil de Cambronero (1833) y el Proyecto de Código Civil de 1836. Respecto al primero, éste llega al final de la "Década ominosa" de Fernando VII, espoleado en buena parte por la codificación de las leyes mercantiles con la aprobación del Código de Comercio de 1829 y la Ley de enjuiciamiento mercantil de 1830. El trabajo fue encargado al ilustre jurista de corte afrancesado Manuel María Cambronero ${ }^{45}$, mediante nombramiento real, que a pesar de la vehemencia puesta en su labor no pudo concluirlo debido a su muerte acaecida poco después. Su obra se ciñó a una parte del ordenamiento jurídico privado -tutela, curatela, ausencia y personas morales-y tomó antecedentes aprovechables del proyecto de $1821^{46}$.

De esta manera, muertos el monarca encargante y el jurista encargado, el nuevo gobierno de 1834, bajo el ministerio de Garelly, antiguo promotor del proyecto de 1821, se crea una comisión especial, formada exclusivamente por juristas de reconocido prestigio, con el encargo de redactar un nuevo Proyecto de Codificación Civil. Dicho encargo se finalizó el 15 de septiembre de 1836, presentado a Cortes

${ }^{42}$ Peset ReIG, Análisis y concordancia del proyecto del Código civil de 1821, Anuario de Derecho Civil, 28 (1975), pp. 29-100, ha estudiado en profundidad el proyecto del año 1821.

${ }^{43}$ Escudero, J. A., Curso de Historia del Derecho. Fuentes e instituciones politico-administrativas (6a edición, 1990), p. 922.

${ }^{44}$ De Castro, F., Derecho civil de España, cit. (n. 33), p. 202.

${ }^{45}$ Manuel María Cambronero (1765-1834) fue doctor en ambos Derechos cuando contaba sólo 20 años de edad. Nacido en Orihuela (Murcia) según narran sus coetáneos perteneció al grupo de los afrancesados. Fue miembro de la Comisión Legislativa del Código de Comercio.

${ }^{46}$ Sobre el proyecto de Cambronero, véase: ANTEQUERA, J. M., La Codificación moderna en España (Madrid, 1886); Baró PAzos, Codificación, cit. (n. 11); Lasso GaITe, Crónica, cit. (n. 24), SÁnchez Román, Estudios de Derecho Civil. Historia General de la Legislación española (Granada 1880); Tomás y VALIENTE, Obras, cit. (n. 10) 
del 16 de noviembre de ese mismo año. Los graves acontecimientos políticos de ese momento con el motín de La Granja, la derogación del Estatuto Real de 1834, la rehabilitación de la Constitución de Cádiz, las importantes presiones foralistas y el cambio de gobierno hubo de dar al traste con el trabajo codificador quedando el proyecto acabado con cuatro libros y casi 2500 artículos metidos en un cajón ${ }^{47}$.

El inicio de la segunda etapa de la codificación, etapa de oficialización de la codificación, viene marcado por el Decreto de 19 de agosto de 1843, bajo el gobierno presidido por José María López, quien, consciente de que el principal escollo interno a la codificación lo constituía la jerarquía de diferentes poderes territoriales, los cuales ejercían su influencia a través de diferentes representantes en Cortes y juristas destacados, nombra la primera Comisión General de Codificación, que dirige Manuel Cortina. El fruto de su trabajo lo constituyen las bases generales con su programa de codificación, consignando en la tercera: "Que el Código Civil comprenderá las disposiciones convenientes para que en su aplicación a las provincias que tienen legislación especial, no se perjudiquen los derechos adquiridos, ni aún las esperanzas creadas por las mismas legislaciones" ${ }^{8}$. Por indicación del presidente de la Sección de Código Civil y "a fin de conciliar en cuanto sea posible las disposiciones de las legislaciones forales con la de Castilla o que merezcan ser examinados para su adopción o abolición en el nuevo Código", se dirige con fecha de 11 de noviembre del mismo año 1843 una comunicación interesando el informe de las Audiencias y Colegios de Abogados de La Coruña y Oviedo sobre las disposiciones que deberían adoptarse acerca de los foros de Galicia y Asturias; a los expresados órganos de Valencia, "sobre las cuestiones de derecho civil que más llamen la atención en las provincias de su territorio y señaladamente sobre sucesiones, censo, uso y aprovechamiento de las aguas"; a los de Granada, acerca del mismo punto del uso de las aguas; a los de Zaragoza, además, sobre los puntos que juzguen más dignos de atención acerca de la patria potestad y derechos respectivos de los cónyuges; y a los de Bilbao "sobre cuanto crea oportuno en materia de sucesiones legitimas y retractos que deban tenerse en consideración por la divergencia de usos y fueros de aquel pais respecto de Castilla" ${ }^{4}$.

Reorganizada la Comisión en $1846^{50}$, el nombramiento de uno de sus miembros y ponente principal García Goyena como ministro de Gracia y Justicia allanó

${ }^{47}$ Sobre el Proyecto de 1836, véase: ANTEQUera, J.M., La Codificación moderna en España, cit. (n. 46); Baró PazoS, Codificación, cit. (n. 11); Lasso Gaite, Crónica, cit. (n. 24); SÁnChez Román, Estudios de Derecho Civil, cit. (n. 46); Tomás y Valiente, Obras, cit. (n. 10)

${ }^{48}$ Comisión de Códigos, Crónica de la Codificación Española, 1 (Madrid, 1970), p. 48.

${ }^{49}$ Cabanas Rodríguez, Desarrollo histórico del Derecho gallego, cit. por RodríGUEZ ENNES, Historia do Dereito, cit. (n. 26), p. 158.

${ }^{50}$ Integraba la Sección primera de la Comisión General de Codificación de 1846, que redactó el Proyecto de 1851, Florencio García Goyena -que la presidió-, Claudio Antón de Luzuriaga y Juan Bravo Murillo, actuando como secretario el Sr. Sánchez Puig. Tal Comisión estableció primeramente unas bases, 53 en total, para la elaboración de un Código civil, cuyo original firmado por Bravo Murillo se encuentra en el archivo de la Comisión General de Codificación. Sobre ello puede verse: LASSO GaITE, Crónica, cit. (n. 24), pp. 157 y ss. 
sin dudas las dificultades ${ }^{51} \mathrm{y}$, por fin, en 1851 ve la luz el proyecto ${ }^{52}$. El proyecto de 1851 modifica sensiblemente el criterio de codificar solamente la legislación castellana puesto que, sin apartarse del mismo, introduce alguna de las especialidades del llamado Derecho foral. Estas introducciones de alguna institución no estrictamente castellana no representa de ningún modo, variar el contenido de que la codificación se realiza sobre y respeto el único Derecho de importancia, a saber la legislación castellana ${ }^{53}$. García Goyena, por su progenie navarra, era consciente de la exigencia de un particularismo jurídico en algunos territorios de la nación ${ }^{54}$, pero su visión como hombre público y con una alta responsabilidad de Estado, le llevó a acometer una serie de reformas en nuestra legislación que tendían insoslayablemente a la homogeneización del Derecho civil en España,

${ }^{51}$ García Goyena era navarro, nacido en Tafalla en 1783. Entre otros cargos ocupó el Ministerio de Justicia en un breve período de tiempo cuando otro jurista prestigioso, Pacheco, ocupó la Presidencia del Gobierno, en incluso esta misma Presidencia del Consejo de Ministros cuando Pacheco dimitió en 1847; en sustitución de Bravo Murillo ostentó además la presidencia de la Comisión General de Codificación, constituida con arreglo al Real Decreto de 19 de agosto de 1843. Evoca la figura de este jurista, más reconocido en América que en España, CASTÁN VÁzQuez, El proyecto de Código civil de 1851 y su influencia en las codificaciones iberoamericanas, en Anales de la Real Academia de Jurisprudencia y Legislación, número especial dedicado al Centenario del Código civil (Madrid, 1988), pp. 263-286. Sobre la difusión del Proyecto de 1851 en los países latinoamericanos, véase, además, del mismo autor, La influencia de García Goyena en las codificaciones americanas, en Homenaje al Profesor Roca Juan (Murcia, 1983), pp.153-161; El Código civil de Andrés Bello, factor de unidad, en Andrés Bello y el Derecho Latinoamericano, Congreso Internacional (Roma, 1981); y Humanismo y Derecho en Andrés Bello, en Anuario de la Facultad de Ciencias Jurídicas y Politicas de la Universidad de los Andes, Mérida (1983-1984), pp. 41-52; De Los Mozos, Algunos aspectos de la influencia hispánica en el Código civil de Andrés Bello, en RGLJ. (1978) p. 458-459, destaca también estos influjos del Proyecto isabelino en el Código Civil de Chile (refiriéndose al mismo y a las Concordancias) señala que fue muy bien recibida en toda América, donde constituye uno de los monumentos jurídicos más valioso de la tradición romanista, y con ello uno de los frutos más logrados de la obra colonizadora de España. Bravo LiRa, Codificación europea e hispanoamericana, en Revista de Estudios Históricos-Jurídicos, 9 (1989), pp. 60-61, en una buena síntesis sobre la identidad del proceso de la codificación europea e hispanoamericana, destaca la utilidad del Proyecto de 1851 gracias a los comentarios de Florencio García Goyena, en la formación de los Códigos civiles de México de 1861, Uruguay de 1869, Argentina y México de 1871, Costa Rica en 1888, y Honduras en 1898

${ }^{52}$ Para una visión amplia sobre el particular véase: RODRíGUEZ EnNES, Florencio García Goyena y la codificación iberoamericana, en AHDE., 76 (2006).

${ }^{53}$ El propio García GoYena, Concordancia, motivos y comentarios del Código civil español (Madrid, 1852), III, p. 256, manifiesta sin ambages su rechazo al particularismo jurídico en estos términos, Referirse de una manera general a costumbres y fueros abolidos tendría visos de una resurrección, aquellos continuarán en el concepto vulgar como leyes del Estado, seguiría la misma confusión que hasta aquí y quedaría frustrado el objetivo de este Código o la unidad constitucional, sería echar nuevamente a los españoles al laberinto de que se les quiere sacar, y ensanchar el abismo que el Código Civil debe cerrar.

${ }^{54}$ Véase al efecto: D'ORs, A., Los derechos civiles regionales en la España moderna, en La formazione storica del Diritto moderno in Europa (Florencia, 1977), pp. 935-941; D'ORs, A. Bonet Correa, En el Centenario del Proyecto Isabelino de Código civil, en Información jurídica, 96 (1951), p. 488. 
sin duda para estructurar el Estado sobre unos mismos principios jurídicos ${ }^{55}$, tal como se preconizaba en la Constitución de 1845.

De acuerdo con estos principios, el proyecto de 1851, que empleó como guía el Code francés y tomó como eje el Derecho castellano entre los diversos Derechos hispánicos, fue, en suma, de corte centralizador y antiforal ${ }^{56}$. García Goyena, basándose en las discusiones del proyecto en el seno de la comisión, elaboró un libro comprensivo de los antecedentes histórico-legales de cada artículo, que ofrecía concordadas todas sus disposiciones con el derecho anterior, e incluso con el derecho comparado con motivos y comentarios sobre cada uno de sus preceptos, fijando su espíritu y resolviendo algunas cuestiones que pudieran suscitarse en su aplicación práctica ${ }^{57}$; y esta interpretación debería reputarse como auténtica, por haber sido discutida y aprobada en el seno de la Comisión que elaboró el proyecto de código. Recientemente ha mejorado el juicio que merece a la doctrina científica del proyecto isabelino. La publicación de materiales inéditos de la Comisión General de Codificación, o el hallazgo de otros nuevos, ha permitido ofrecer una nueva visión de la significación de este buen proyecto en el proceso de la codificación civil en España ${ }^{58}$. A mayor abundamiento, el citado proyecto, aunque técnicamente mejorado, fue el modelo y punto de partida del posterior código, que en opinión de Lacruz recoge en un $65 \%$ los artículos del proyecto isabelino ${ }^{59}$.

La pertinencia y la calidad jurídica de este código ha sido resaltada por numerosos autores, bastando para muestra de la impresión general de la doctrina, la observación de Tomás y Valiente que expresó que "en 1851 se supo hacer un código, pero no se quiso promulgarlo" ${ }^{60}$. En cuanto a los motivos que dejaron a este texto en un simple proyecto, la mayor parte de los autores insisten en su sesgo

${ }^{55}$ Esta postura de que la codificación se limitaba al derecho castellano era un lugar común en la época. TomÁs y VALIENTE, Manual de Historia del Derecho Español (Madrid, 1983), p. 578, recoge las manifestaciones de Lorenzo de Arrazola, jurista coetáneo del proyecto isabelino, cuando indica que entre las legislaciones que dominan en España, nos parece obró con acierto eligiendo a las de Castilla. Ninguna otra de las que rigen en las comarcas es tan perfecta, tan completa, tan estudiada; ninguna otra a sido objeto de tantos y tan concienzudos trabajos; ninguna otra tiene vida y existencia propia en todas sus partes...

${ }^{56}$ Rodríguez EnNES, Florencio Garcia Goyena y la codificación iberoamericana, cit. (n. 52), p. 709.

${ }^{57}$ García Goyena, Concordancias, cit. (n. 53). La edición de Zaragoza de 1974 aparece precedida por una "Nota preliminar" de LACRUZ BERDEJo, Las Concordancias de García Goyena y su valor para la interpretación del Código civil, en la que muestra la importancia de este trabajo de García Goyena (al que califica de "libro clave”), para la correcta hermenéutica del Derecho civil contenido en el Código. Esta Nota se publica también en la RCDI., 50 (1974), p. 289-302.

${ }^{58}$ Así Salvador Coderch en sendos artículos publicados como El Proyecto de Código de derecho civil de 1851 y el Derecho civil catalán, en RJC. (1980/1981), pp. 49 ss.; y (1982), pp. 313 y ss., ofrece un análisis sobre el proyecto en relación con instituciones centrales del derecho catalán, como son la legítima, enfiteusis y rabassa morta, desde una perspectiva en parte superadora de anticuadas corrientes de autores regionalistas, que achacan al Proyecto de 1851 su promulgación como ley.

${ }^{59}$ Lacruz Berdejo, "Nota preliminar", cit. (n. 57), pp. iv-v.

${ }^{60}$ Tomás y Valiente, Códigos y Constituciones, cit. (n. 14), p. 27 
antiforal ${ }^{61}$, argumento que se revela especialmente en algunos preceptos, como el que prohíbe en la regulación económica del matrimonio que los esposos pacten un régimen de bienes conforme a fueros y costumbres (artículo 1237). Incluso, de forma taxativa, el último de los artículos deroga el conjunto del derecho foral y consuetudinario $^{62}$. Semejante radicalismo, desconocedor de la vitalidad y empuje de la legislación foral, fue una de las causas que impidieron que el proyecto llegara a buen término ${ }^{63}$. Hubo otras, sin duda, como la apuntada por Roca: "las luchas internas de un país que no había acabado de encontrar su organización y que quería copiar los resultados de una revolución (francesa) sin hacerla"64. Ligadas con esto último figuran sus posiciones, también tajantes, en otras cuestiones que rozaron los principios e intereses de la Iglesia ${ }^{65}$, cuestión por lo demás trascendente cuando ese mismo año se estaba firmando el concordato ${ }^{66}$.

${ }^{61}$ Así entre otros, el ilustre penalista Groizard, De la Codificación en España, en RGLJ., 21 (1862), pp. 17-21. reconoció los verdaderos obstáculos que se presentarían en España en el intento uniformador, consideraba que entre la legislación de Castilla y la de Aragón habìa más discordancia que entre aquella y la de la mayor parte de las Naciones europeas; y que tal era la gran dificultad de la codificación en España; y añadìa: "No decidimos que la función es imposible, sostenemos sólo que es difícil y peligrosa, si no se toman en consideración antecedentes históricos, y sobre todo si no se preparan los ánimos a favor de las nuevas leyes”. Por su parte, dos décadas más tarde, Martínez Alcubilla, Boletín juridico-administrativo, apéndice al Diccionario de la Administración española peninsular y ultramarina. Anuario de 1880 (Madrid, 1880), p. 40, justifica el fracaso del Proyecto de 1851 en estos términos, "porque han sido causas bastantes poderosas a impedirlo, el natural afecto que varias provincias de España que tiene a los fueros que las rigen, y sus fundados temores de que antiguas y respetadas instituciones, que afectan a la manera como en ellas está constituida la familia o la propiedad, desapareciesen por completo o se resintiesen profunda y dolorosamente en aras del principio unitario en todo su rigor aplicado".

${ }^{62}$ Artículo 1992: "Quedan derogados todos los fueros, leyes, usos y costumbres anteriores a la promulgación de este Código, en todas las materias que son objeto del mismo, y no tendrán fuerza de ley, aunque no sean contrarias a las disposiciones del presente Código".

${ }^{63}$ GÓMEZ de la SERna, Estado de la codificación al terminar el reinado de doña Isabel II, en $R G L J ., 39$ (1871), pp. 284 ss., liga la oposición anti-uniformista al influjo de la Escuela Histórica savignyana. Había entonces empezado en nuestra patria a tener influencia la escuela histórica alemana y esto hacía que se mirase con recelo la conveniencia de la Codificación del Derecho civil, lo que algunos años antes parecía natural, sencillo y no expuesto a graves inconvenientes Sobre el alcance e influjo de esta Escuela, véase: ATARD, R., La Escuela Histórica del Derecho (Madrid, 1908); GIL CREMADES, El reformismo español. Krausismo, escuela histórica, neotomismo (Barcelona, 1969), pp. 123-154. La crítica de antiforalismo aparece fundamentada en el precepto que acabamos de transcribir. Con todo, cabe preguntarse qué otra formulación cabe incorporar a un código civil que, como de su propia naturaleza habría de inferirse se convertiría en ley general en todo el Reino. El sistema que se establece ha de ser unitario, lo que es consustancial con la idea de código.

${ }^{64}$ Roca TRías, La Codificación y el Derecho foral, en RDP. (1978), p. 612.

${ }^{65} \mathrm{El}$ artículo 608 no reconocía a la Iglesia capacidad para adquirir bienes inmuebles por vía testamentaria y se exigía la autorización del Gobierno para la adquisición de bienes muebles.

${ }^{66}$ Rodríguez EnNes, Historia, cit. (n. 26), pp. 161-162. En este sentido, explica este autor que también tuvo algo que ver con poner el Proyecto de 1851 en vía muerta su regulación del matrimonio y del divorcio civil no vincular y la atribución de tal materia a los tribunales civiles, innovación que en opinión de ANTEQUERA, La Codificación moderna de España, cit. (n. 47), p. 69, no podían tener cabida en el Código Civil de una nación católica. El dictamen de la universidad 
La tercera de las fases del proceso codificador, la etapa intermedia, viene definida por un cambio en la estrategia. Como habíamos apuntado, planteadas en los términos expuestos las vicisitudes de la codificación del Derecho civil, se hizo evidente la necesidad de proceder a la unificación de algunas instituciones del derecho privado, sin perjuicio de persistir en el empeño de alcanzar la homogeneidad de la legislación civil. A esta necesidad responden distintos tipos de realizaciones legales, conocidas como "leyes especiales" como son las Leyes hipotecarias de 1861 y 1869, la Ley del Notariado de 1862, la de Matrimonio civil de 1870 y finalmente la de Registro civil del mismo año. La finalidad de las leyes especiales aparece explícitamente recogida en la reunión del Congreso de Jurisconsultos, celebrada en octubre de 1863. En concreto, en su base $6^{a}$, se establece que el medio de realizar prontamente la Codificación, y de que sea "recibida sin repugnancia [...] es que vaya precedida de leyes especiales que le preparen el camino"67.

Con referencia a la Ley hipotecaria, el fenómeno de la crisis finisecular estuvo precedido y acompañado de un proceso de profundización y expansión de las instituciones jurídicas y administrativas propias de un ordenamiento burgués de la sociedad, lo que conllevaba por su propio carácter y significado un deterioro notable de la situación jurídica y de las perspectivas de futuro de instituciones como la propiedad compartida ${ }^{68}$. En los años 60 se asumió por primera vez la elaboración de una Ley hipotecaria ${ }^{69}$. Con ella se pretendía dar sanción definitiva

salamantina fue concluyente sobre este particular: "[...] considerando que la disciplina común de la Iglesia atribuye el conocimiento de las mismas (se refiere a las causas matrimoniales) a los Tribunales de los Obispos [...] que las leyes de España se vienen conformando desde la más remota antigüedad con este sistema que es en general en los países Católicos [...] no hay razones que aconsejen la introducción de una novedad trascendental en cuya consecuencia podría turbarse la armonía entre la Iglesia y el Estado" [en Colección de Memorias y discursos inaugurales y otros trabajos de la Academia de Jurisprudencia y Legislación]; en este sentido, son especialmente ilustrativos el de MONTERo Ríos sobre la "Doctrina de la Iglesia sobre sus relaciones con el Estado en las diferentes épocas de la historia", pronunciando en 1875, y el de CHARRín Tigero, sobre "Relaciones entre la Iglesia y el Estado", de 1876. Más modernamente, acerca de la posición de la Iglesia contra la ecléctica regulación de la institución del matrimonio prevista en el Proyecto, véase CARRIÓn, Historia y futuro del Matrimonio civil en España (Madrid, 1977); RoldÁn BERDEjo, La Ley del Matrimonio civil del 1870. Historia de una ley olvidada (Granada, 1980); y, muy especialmente, CRESPO DE Miguel, El matrimonio en los dictámenes oficiales sobre el Proyecto de Código civil español de 1851, en RGLJ. (1987), pp. 653-728.

${ }^{67}$ Palma y Luján, Congreso de Jurisconsultos, en RGLJ., 23 (1863), p. 306; Lasso Gaite, Crónica, cit. (n. 24), IV, pp. 309-310.

${ }^{68}$ Baz VICENTE, Señorío y propiedad foral de la alta nobleza en Galicia (siglos XVI-XX). La casa de Alba (Madrid, 1996), p. 373.

${ }^{69}$ Para la confección de la ley sobre la hipoteca, el Gobierno recomendó a los miembros de la Comisión la utilización de los materiales que en relación con el régimen hipotecario habían sido redactados desde los inicios del proceso codificador. La Comisión, en atención a los antecedentes obrantes en su poder, discutió y redactó unas Bases que se sustentaban sobre los principios de la obligatoriedad de la inscripción en los registros públicos de todos los derechos de cualquier especie que se adquieran y en el la especialidad absoluta del sistema hipotecario, lo que vendría a suponer como advierte CáRDEnas [en Diario de Sesiones de Cortes, Congreso, 1858, I, p. 248] -a la sazón de su presidente- la necesidad de definir y determinar así la naturaleza, extensión y límites de los derechos que se constituyeran sobre bienes inmuebles, para evitar el confusionismo 
a los derechos de la propiedad adquiridos al amparo, bien de un régimen señorial abolido, bien de una legislación desamortizadora que no contaba con el beneplácito de todos los sectores de poder implicados en el régimen del moderantismo liberal establecido. Se trataba, en definitiva, de dotar a la propiedad de los atributos de publicidad y de seguridad necesarios para hacer realidad el "sagrado respeto" que la definía en un estado de derecho burgués-liberal, y de facilitar ya en toda su extensión su libre circulación así como la organización del crédito agrario. La Ley hipotecaria de 1861, que entró en vigor en 1863, puso de manifiesto el aludido contraste que emana de la Comisión General de Codificación desde mediados del siglo XIX y la naturaleza del régimen de la propiedad de la tierra español, agarrotado por la existencia de múltiples dominios y regido por una normativa consuetudinaria y privada que era difícil de encajar en los límites de Derecho civil que aquella Comisión estaba elaborando ${ }^{70}$. Se trata además de una ley general en todos los territorios de la Monarquía que pretende por tanto la uniformidad legal. Precisamente por su unitarismo se originó una cierta oposición, aún no suficientemente estudiada, por parte de los propietarios y juristas de determinadas regiones que disfrutaban de regímenes particulares en materia de propiedad territorial ${ }^{71}$. Esta reacción, y el cambio político provocado por la revolución de 1868, hizo necesaria la elaboración de varios trabajos que reformaron la Ley de 1861, principalmente en sus disposiciones transitorias, que culminarán con la promulgación de la nueva Ley hipotecaria de 21 de diciembre de $1869^{72}$.

Finalmente, es digno de destacar, dentro de este estadio, el proyecto de libro I del código civil de Romero Ortiz en 1869, proyecto que se presentó a su aprobación en Cortes como ley especial y que trataba esencialmente de los derechos individuales, siguiendo el mandato ideológico de la Revolución de 1868 que dio lugar al sexenio democrático. Este texto guardaba, por su contenido, especial relación con la parte dogmática de una constitución cuya realización, en 1873, se quedó también en fase proyectiva.

La fase definitiva del proceso de codificación civil español, la etapa de culminación, comienza, bajo el influjo de la Restauración monárquico-borbónica y su posterior asentamiento jurídico con la duradera Constitución de 1876, con el nombramiento de la Comisión General de Codificación mediante Decreto de 10 de mayo de 1875 , comité que fue parcialmente sustituido por el definitivo mediante un nuevo Decreto de 2 de febrero de 1880. En ambas delegaciones destacó Alonso Martínez como bastión definitivo de aprobación del Código Civil. La nueva Comisión, que trabajó fundamentalmente sobre la base del malogrado proyecto de 1851, dio sus primeros pasos constatables con el Proyecto de ley de bases de Alonso Martínez de 22 de octubre de 1881, y empezó a encauzar el principal

con otros derechos y como consecuencia de éste la liberación de las hipotecas tácticas y de las responsabilidades ocultas a que puedan estar afectos los bienes inmuebles.

${ }^{70}$ Ibíd., p. 298.

${ }^{71}$ A esta conclusión llegan para el caso de Navarra, Contreras y Martínez Aguirre, La actitud de Navarra ante el Código civil, en Centenario del Código Civil (Madrid, 1990), I, p. 517-530.

${ }^{72}$ Rodríguez EnNes, Historia, cit. (n. 26), p. 165. 
escollo codificador en España, las tensiones foralistas, a través del Acuerdo con los territorios forales (redacción de los libros III y IV) de 1882. Otro destacado miembro de la Comisión, Francisco Silvela, fue el protagonista del Proyecto de ley de bases de 1885, que pretendía representar el continuismo en los trabajos de la Comisión, que se veían frecuentemente dinamitados por presiones de diferentes intereses. El articulado de la Ley de bases fue exclusivamente aprobado por el Senado, pero, igual que ocurriera con el texto de Alonso Martínez, no fue definitivamente aprobado por las Cortes. Finalmente el Congreso de Jurisconsultos de 1886 resultó clave para mostrar la predisposición a la uniformidad legislativa civil. La pregunta sobre si había llegado en España el momento de codificar el Derecho civil fue contestada afirmativamente por trescientos cuarenta y un congresistas de un total de cuatrocientos.

Después de las modificaciones parlamentarias realizadas sobre el texto de Silvela se aprobó la Ley de bases de 1888 que contenía las principales orientaciones hacia la redacción definitiva del Código. Resumidamente, se establecía que el Gobierno quedaba facultado para publicar un texto redactado por la Comisión de Codificación que, tras los pasos parlamentarios oportunos, y siguiendo la base jurídica fijada en el proyecto de 1851, y con respeto a la conservación del Derecho foral en las provincias y territorios donde éste existía, habría de entrar en vigor como Código Civil el 1 de mayo de 1889, si bien una corrección de última hora hizo que el texto definitivo corregido adquiriese nueva y concluyente vigencia el 24 de julio de ese mismo año.

El dilatado proceso y las innumerables voluntades jurídicas y políticas que llevaron a la definitiva aprobación del Código Civil en 1889 hacen que este texto sea la síntesis de todos los esfuerzos desplegados a lo largo del siglo XIX. Sin lugar a duda destaca en cuanto a influencia, de entre todos los proyectos, el de 1851, si bien los demás no están, en absoluto, desprovistos de cierto valor y significación en la historia de la codificación. Cada uno de ellos "son fiel muestra del espíritu y la mentalidad jurídica de la época en que se elaboran; son hitos que van jalonando el camino hacia la consumación del proceso de la codificación"73. De otro lado, y a modo de conclusión podemos afirmar que el Código Civil español puede ser considerado como el reflejo del Derecho histórico nacional.

\section{CONSTITUCIONALISMO, CODIFICACIÓN Y UNIFICACIÓN JURÍDICA}

Constitucionalismo y codificación son conceptos que constituyen la máxima expresión de un nuevo orden jurídico surgido con las revoluciones liberales y que son producto de una misma corriente filosófica, el iusnaturalismo racionalista ${ }^{74}$. Su ideario propone la existencia de unos derechos individuales de orden superior e inalienable entre los cuales destacan la libertad, la igualdad y la propiedad privada. Los Derechos se entienden previos a cualquier constitución y no dependientes de ella. constitución y codificación se convierten en instrumentos básicos para la

\footnotetext{
${ }^{73}$ Baró Pazos, Codificación, cit. (n. 11), 284.

${ }^{74}$ Ibíd., p. 14.
} 
implantación y defensa de tales derechos. Una, porque los dogmatiza como una parte básica de la estructura social, política y estatal, y otra, porque define el ámbito para la realización de tales Derechos en el cual la igualdad formal o jurídica debe ser contenido y límite, y ésta precisa de uniformidad normativa en el territorio sobre el que se proyecta la norma normarum. Constituciones y códigos responden a un mismo impulso racionalizador, uniformista e igualitario ${ }^{75}$.

Las raíces ideológicas y el soporte socioeconómico de la codificación y de las constituciones son insoslayablemente comunes. Si las constituciones representan la organización del Estado liberal-burgués de Derecho, los códigos pretendieron contener el resto de la organización jurídica de la sociedad burguesa. Es más, en buena política legislativa las constituciones debieron preceder a los códigos ya que significan respecto a ellos el presupuesto lógico y jurídico fundamental. El modo de creación de Derecho del Estado liberal consiste, pues, en el constitucionalismo y la codificación.

Los dos conceptos devienen en símbolos jurídicos característicos de una época y están profundamente ensamblados, por la afinidad de los principios que a uno y otro corresponden, y por la pretensión de alcanzar una finalidad común: la igualdad jurídica que supere todos los privilegios y logre la imparcialidad legal todos los ciudadanos. Ambos son también los modos fundamentales de la legislación liberal que pretenden al mismo tiempo unificar legal y políticamente el Estado.

Partiendo de ello, el paralelismo existente entre los movimientos constitucionalista y codificador en nuestro país resulta tan evidente como insuficientemente estudiado. Ambos fueron el fruto de preocupaciones sociales, políticas y jurídicas similares. A ello se unió la irrupción del criterio de uniformidad legislativa que todas las constituciones decimonónicas preceptuaron y que, con los matices aportados por los movimientos forales que no querían perder determinadas especificidades normativas de sus territorios propios, acabó siendo aceptado como un elemento indispensable del progreso jurídico europeo, de la superación de los arcaísmos del "Ancien Régime", del paradigma de la libertad y la igualdad liberal, y todo al margen del componente ideológico que, como se ha visto, acabó por condicionar los textos constitucionales de esta época ${ }^{76}$. Es por ello que "cuando precede el fenómeno constituyente se cuiden los códigos políticos de anunciar como una garantía más la codificación civil y penal, casi predicando con ello un nuevo y único evangelio, cuyos dogmas se aplicasen a todas las esferas" 77 .

En España la relación de ambos fenómenos aparece marcada por el hecho de que la codificación aparece inducida por el constitucionalismo. Aún más, la realización de la misma constituye un mandato constitucional"78. Así lo hemos comprobado en el breve repaso a las diferentes constituciones decimonónicas que recogían esa avidez codificadora, ese afán por cumplir tal requisito que se

\footnotetext{
${ }^{75}$ Escudero, J.A., Curso., cit. (n. 43), p. 905.

${ }^{76}$ Mirete Navarro., M. Alonso Martínez y la polémica sobre la codificación en España, en Anales de la Universidad de Murcia. Derecho, 33 (1974-75) 1-2.

${ }_{77}$ Pérez Serrano, Constitucionalismo y Codificación, en Revista General de Legislación y Jurisprudencia (Madrid, 1953), p. 94.

${ }^{78}$ Baró Pazos, Codificación, cit. (n. 11), p. 15.
} 
hacía consustancial a la propia idea de constitucionalismo. Algún autor lo pone de relieve manifestando que la codificación "se expresa por la constitución y se encierra en ella" ${ }^{\prime 2}$. Así, hemos reseñado en el sucinto examen introductorio de la historia constitucional española, como diferentes textos decimonónicos recogían en su articulado este mandato codificador. Estos preceptos encierran el encargo propio y la consecuencia del señalado principio de igualdad ante la ley de todos los españolas y son la superación lógica de los privilegios estamentalistas. Y es que la codificación civil sufrió análogos avatares que el Constitucionalismo, aunque no se distinga una cronología similar entre ambas situaciones.

Clavero define la relación originaria entre los dos procesos de manera que fue la constitución la que proporcionó a la codificación su primer componente básico: el sujeto unitario. Para llegar a él hubo de obrarse una "revolución normativa". Aparecieron las constituciones que con sus declaraciones de derechos, desplegados de forma igualitaria por todo el territorio, acabaron por crear el sujeto unitario al que habrían de aplicarse. La base es el nuevo sujeto que se concibe y respecto al cual puede predicarse la norma. Sólo entonces puede pasarse del significado estatuido al estatuyente que concibe el Derecho codificado. declaraciones de derechos y constituciones ingresan en el campo de la codificación al tiempo que otras normas pretéritas con denominaciones de código lo abandonan. "La constitución es código y semilla de códigos" ${ }^{\circ 0}$. Sin ella los códigos no se definen. La historia de la codificación sigue su propia secuencia: revolución, declaración, constitución y códigos ${ }^{81}$. Pero hemos de tener en cuenta también que la codificación sirvió de elemento esencial para la adaptación de los distintos sectores del ordenamiento jurídico al régimen constitucional que iban marcando los diferentes textos constitucionales. La importancia constitucional es tanta que en la historia de la codificación europea debería partir, actuando como elemento esencial, del constitucionalismo norteamericano ${ }^{82}$. Y es que para la codificación es tan fundamental la revolución liberal como la revolución constitucional.

De esta forma, la codificación cumplió la función de unificar, suprimiendo fraccionamientos, subdivisiones, pluralidad de situaciones. El criterio unificador se convirtió en principal impedimento para lograr aquélla, pero también en sustancial anhelo, requisito y meta. Unificar supone, además, una operación que se desarrolla en un ámbito geográfico o territorial, dirigida a suprimir las fuentes jurídicas locales y sustituirlas por una regla única y uniforme. Históricamente ha sido a menudo una operación difícil, compleja y traumática, porque detrás del fraccionamiento geográfico del derecho no se escondían, como frecuentemente se ha dicho, sólo miedos ancestrales o cómodos letargos. A sus importantes obstáculos se unían los esfuerzos de todas las minorías -étnicas, lingüísticas, religiosas, económicas- de no ser ahogadas por un derecho unitario, que, entendían

${ }^{79}$ Clavero, B., Codificación y constitución, paradigmas de un binomio, en Quaderni Fiorentini, 18 (1989), p. 83.

${ }^{80}$ Ibíd., p. 82.

${ }^{81}$ Ibíd., p. 84.

${ }^{82}$ COMANDUCCI, P., La costituzionalizzazione americana, un capitolo nella storia della cultura giuridica europea, en Materiali per una Storia della Cultura Giuridica, 17 (1987). 
ellas, tendía a aplastarlas y a obligarlas inevitablemente a alinearse sobre esquemas y modelos considerados extraños y, por consiguiente, ni ambicionados, ni compartidos. Esto explica también que, en países como España, esta operación unificadora durase decenios porque las minorías articularon su propio disenso y obstaculizaron, como se ha dicho, eficazmente, las aspiraciones centralizadoras de los liberales del siglo XIX ${ }^{83}$.

La codificación se convierte no sólo en un mero instrumento jurídico que proporciona coherencia y seguridad jurídica al sistema legal sino que, sobre todo, representa un elemento básico del ideal económico burgués que precisa de uniformidad legislativa como precondición para la expansión inversionista, financiera y especulativa, y que precisa de un poder centralizado que iguale a toda la población y no permita las arbitrariedades legislativas de poderes oligárquicos o caciquiles que aprovechan la lejanía territorial de la administración central. En este sentido el código sirve a su vez de unidad política ${ }^{84}$. Así dirá Lasso que la codificación consiste en la formación de un sistema completo de Derecho. Un sistema que se propone la unificación y la certeza del Derecho ${ }^{85}$.

La línea del pensamiento uniformista, consustancial al movimiento codificador, se confirma con la simple comparación del repetido artículo 258 de la Constitución de 1812 con el artículo 4 de las sucesivas Constituciones de 1837 y 1845. En efecto, el primero de ellos previene que "unos mismos Códigos regirán en toda la Monarquía, y en ellos no se establecerá más que un solo fuero para todos los españoles en los juicios comunes, civiles y criminales"; y según el artículo 4 de la Constitución de 1845 "unos mismos Códigos regirán toda la Monarquía". Como puede apreciarse, unidad legislativa absoluta en las Constituciones de 1837 y 1845 , que alumbraron el proyecto de código civil de 1851 . No se olvide además que este designio uniformista, fue seguramente el factor determinante que, como tuvimos ocasión de analizar, llevó al fracaso del código civil. Lo cual tal vez explique que se volviera al conocido criterio de la primera Constitución de 1812, es decir, uniformidad legislativa con matizaciones ${ }^{86}$.

De esta manera, tal y como ocurriera en Alemania a principios del diecinueve ${ }^{87}$,

\footnotetext{
${ }^{83}$ Rodríguez EnNes, Historia, cit. (n. 26), p. 148.

${ }^{84}$ Mirete Navarro, M. Alonso Martínez y la polémica sobre la codificación en España, cit. (n. 76)

${ }^{85}$ Lasso Gaite, Crónica, cit. (n. 24), p. 11.

${ }^{86}$ Puig Ferriol, El denominado problema foral, cit. (n. 35), p. 1621, en la que añade, Así, el artículo 91-3 de la Constitución de la nación española de 6 de junio de 1869 prevenía que unos mismos códigos regirán en toda la Monarquía, sin prejuicio de las variaciones que por particulares circunstancias determinen las leyes; que se reproduce en el artículo 75-1 de la posterior Constitución de la Monarquía española de 1876.

${ }^{87} \mathrm{La}$ controversia entre los defensores de la codificación alemana, defendida por Thibaut, y los defensores de la impertinencia de tal unificación surgió a raíz de una pequeña obra del primer autor sobre la necesidad de un Derecho civil general para Alemania, datada en 1814 y rápidamente respondida por Savigny ese mismo año. Este asunto puede consultarse con profundidad en Thibaut - SAvigny, La codificación (trad. esp. Díaz García, Madrid, 1970). También, Thibaut, A.F.J., Sobre la necesidad de un Derecho civil general para Alemania (Heidelberg, 1814); y su oportuna respuesta a manos de VON SAVIGNY, F.K., De la vocación de nuestra época para la legislación y la ciencia del derecho (Heidelberg, 1814, trad. al español Posada, A., Buenos Aires, 1977).
} 
cuya tardanza en realizar la obra codificadora giró en torno a la controversia jurídica sobre la oportunidad de la codificación y dio lugar a la aparición de la pandectística, corriente jurídica que racionalizó y sistematizó el Derecho civil romano, en España la misma discusión motivó el retraso en la elaboración del código civil ${ }^{88}$. Los prosélitos de la codificación, encabezados por Alonso Martínez ${ }^{89}$, defendían la necesidad y conveniencia de la agrupación de las normas jurídicas civiles en aras de los citados ideales de igualdad y seguridad jurídica. Los detractores de la sistematización normativa, en cuyo frente destacaba Durán i Bas, con el apoyo del movimiento foralista en diferentes regiones españolas y, fundamentalmente, en Cataluña, Galicia y País Vasco, entendían que el derecho, como creación del espíritu del pueblo, precisa de un momento de maduración oportuno para su codificación y que, por entonces, aún debía esperar ${ }^{9091}$.

${ }^{88}$ No obstante, sobre la citada polémica en torno a la codificación alemana, observa TOMÁs y Valiente, Códigos y Constituciones (1808-1978), cit. (n. 14), p. 28, que se ha exagerado su influencia a la hora de justificar el retraso de la codificación española. A su juicio, no está demostrado que en España todos los juristas de la primera mitad del siglo XIX leyeran directamente a Kant o a Hegel, ni siquiera a Thibaut o Savigny. Entre nosotros el nivel filosófico de la polémica se trivializó. El conocimiento de los escritos de Savigny fue de segunda mano y tardío. Antes de la recepción de la Escuela Histórica en Cataluña hubo, durante la década de 1840, en Madrid y en Sevilla, algún eco o noticia aislada de ella; pero se trata de una introducción inicialmente tímida, académica y alejada de las implicaciones políticas (de política legislativa y de política nacionalista) que el historicismo conservador de Savigny y de sus discípulos encerraba. Es más, el aplazamiento que Savigny logro en Alemania para la formación de BGB. fue utilizado, como él siempre anunció, como ocasión para la formación de una ciencia alemana del Derecho (y más en particular del Derecho civil) que acabó sistematizando de un modo formal y racionalista unos dogmas construidos no sobre la experiencia histórica alemana, sino sobre el Derecho romano de las Pandectas (pandectística). Nada de eso se pretendió hacer en España, ni ciertamente se hizo (Rodriguez EnNes, Historia, cit. (n. 26), nt. 469).

${ }^{89}$ Lo declaro franca y noblemente, mi sueño dorado es la publicación del Código Civil, Alonso Martínez, Cuál es y cuál debe ser el estado de la legislación en España, discurso de la solemne apertura de los Tribunales el 15 de septiembre de 1881 (Madrid, 1881).

${ }^{90} \mathrm{El}$ enfrentamiento dialéctico se hizo patente y manifiesto en la cámara legislativa. Así Durán i Bas, dirá: "Ciertamente señores Diputados hay completa discordancia entre el criterio del señor Alonso Martínez y el mío. [...]. La unificación podrá ser un bien para las naciones, podrá ser tendencia de nuestra época, podrá ser un desiderátum de ciertas escuelas que paulatinamente se consiga, ese bien, ese desiderátum, esa tendencia ha de subordinarse a la influencia de ciertas condiciones históricas de las naciones [...]" (en Diario de sesiones del Congreso de los Diputados, 19 de junio de 1885, núm. 177). De otro lado, el sustento filosófico de la postura no codificadora seguía las tesis de Savigny: "En el seno de toda sociedad, y desde sus primeros albores, se forma un espiritu propio, peculiar, exclusivamente suyo, que la anima, que la mueve, que la acompaña en todas las manifestaciones de su vida [...]" [DuRÁ I BAS, Estudios Políticos y Económicos (Barcelona, 1856)]. Sobre los adversarios de la codificación véase, entre otros: Fernandez Álvarez, O Pensamento iusfilosófico de Alfredo Brañas en relación co do seu tempo (Santiago de Compostela, 2002); FIGUERAS PAMIES, La escuela jurídica catalana frente a la codificación español, Durán $i$ Bas, su pensamiento jurídicofilosófico (Barcelona, 1987); GIL CREMADES, El reformismo español. Krausismo, escuela histórica, neotomismo (Barcelona, 1969); GONZÁLEZ VICEN, La Escuela Histórica del Derecho, en Anales de la Cátedra Francisco Suárez, 18-19 (1978-1979); VALLET DE GoYTISOLO, La polémica de la Codificación, la Escuela Filosófica y la Escuela Histórica, en Anales de la Real Academia de Legislación y Jurisprudencia, 19 (1988).

${ }^{91}$ Para una profundización sobre esta controversia jurídica con intervenciones parlamentarias 
Sin embargo, el principal obstáculo que motivaba la contumaz oposición a la codificación no era tanto la cuestión filosófica proveniente de la ciencia jurídica alemana sino el peligro de la uniformidad jurídica. El enemigo no era la sistematización sino la igualación jurídica que enrasaría todo el territorio estatal sin atender a peculiaridades socioeconómicas o a tradiciones históricas. Detrás de una loable lucha por el mantenimiento de institutos jurídicos idiosincráticos de los pueblos se hallaba, sin lugar a dudas, la pérdida de hegemonía real que suponía para los poderes locales este fenómeno de la unificación ${ }^{92}$. A este respecto, desde sus propios orígenes, el constitucionalismo contemporáneo en España se ha definido frente a la existencia de los derechos forales en cuanto que derechos históricos ${ }^{93}$. Las constituciones que acudían a la fundación de un nuevo sistema jurídico y de los derechos forales de determinación histórica eran, justamente realidades antagónicas; las primeras nunca han reconocido o ni siquiera mencionado a los segundos, rechazándolos siempre implícitamente en su proyecto de codificación del Derecho ${ }^{94}$. Y es que el concepto de "derecho foral", como derecho particular de algunos territorios por razón de permanencia histórica, se había formado a lo largo del XIX al margen de las constituciones ${ }^{95}$.

Por otro lado, el largo período de tiempo que transcurrió entre la Constitución de 1812 y la entrada en vigor del Código en 1889 no se utilizó para crear una ciencia jurídica civil propia con suficiente empaque para ser incluida en un código de leyes civiles y por ello hubo de recurrirse al modelo del código napoleónico, adaptándolo a nuestro país ${ }^{96}$. Aún así, el Proyecto de Código Civil de 1851 y la labor del jurista García Goyena contribuyeron decisivamente en la mejora de la literatura jurídica de la segunda mitad del diecinueve y resultaron determinantes para que el Código finalmente aprobado se distanciase del Code napoleónico, mostrando más empatía con las instituciones propias del Derecho nacional. Este arrimo al derecho autóctono del país y de ciertas regiones, así como el respeto a ciertas peculiaridades forales resultó definitivo para vencer la oposición foralista y lograr así el acuerdo mínimo logrado en 1889.

de ambos contendientes dialécticos véase: Mirete Navarro, M. Alonso Martínez, cit. (n. 76); Gómez Mampaso, Alonso Martinez y la Codificación Civil, en Anales de la Real Academia de Jurisprudencia y Legislación, 19 (1988).

${ }^{92}$ Sobre este asunto resultó fundamental, a nivel genérico, la obra de TARELLO, G., La ideologie della codificazione. Del particolarismo giuridico alla codificazione napoleónica (Genova, 1969), que es como la primera edición de su Storia della cultura giuridica moderna, I: Assolutismo e codificazione del diritto (Bolonia, 1976).

${ }^{93}$ En efecto, la aspiración de lograr una codificación de sesgo unitario se deja sentir en todos los textos constitucionales del siglo XIX, desde el Estatuto de Bayona (artìculos 96 y 113). Los artículos concretos de las siguientes constituciones decimonónicas en que se plasma el anhelo codificador pueden verse recogido en Alejandre García, Derecho del constitucionalismo y de la codificación (Sevilla, 1978), pp. 125 y ss.

${ }^{94}$ Clavero, El Código y el fuero (Madrid, 1982), p. 21.

${ }^{95}$ El Derecho foral asume categoría en la enseñanza universitaria tras la frustración del Proyecto de Código Civil de 1851, dentro de la asignatura de "Historia e instituciones del Derecho civil español común y foral” al menos desde 1857.

${ }^{96}$ Sobre este tema véase: Clavero, B., La gran dificultad. Frustración de una ciencia del Derecho en la España del siglo XIX, en Ius Commune, 12 (1984). 


\section{BiBLIOGRAFÍA}

Alejandre García, Derecho del constitucionalismo y de la codificación (Sevilla, 1978).

Alonso Martínez, Cuál es y cuál debe ser el estado de la legislación en España (Madrid, 1881).

Alonso PÉrez, Ideal codificador, mentalidad bucólica y orden burgués en el Código civil de 1889, en Centenario del Código Civil (Madrid, 1990), I.

Álvarez, O Pensamento iusfilosófico de Alfredo Brañas en relación co do seu tempo (Santiago de Compostela, 2002).

ANTequera, J. M., La Codificación moderna en España (Madrid, 1886).

Arrazola, L., Enciclopedia Española de Derecho y Administración (Madrid, 1856), IX.

ATARD, E., El constitucionalismo español, 1808-1987. Ensayo histórico-jurídico (Valencia, 1988).

Atard, R., La Escuela Histórica del Derecho (Madrid, 1908).

Baró Pazos, La codificación del Derecho civil en España (1808-1889) (Santander, 1993).

BAZ VICENTE, Señorio y propiedad foral de la alta nobleza en Galicia (siglos XVI-XX). La casa de Alba (Madrid, 1996).

Bravo LiRA, Codificación europea e hispanoamericana, en Revista de Estudios HistóricoJurídicos, 9 (1989).

Cambronero, Discurso sobre la necesidad de una nueva Legislación para las provincias españolas y medios de formarla (Madrid, 1810).

Cano Bueno, Materiales para el estudio de la Constitución de 1812 (Madrid, 1989).

CÁNOVAS SÁNCHEZ, El moderantismo y la Constitución española de 1845 (Madrid, 1985).

CARONI, Pio, Lecciones catalanas sobre la codificación (Madrid, 1996).

CARrión, Historia y futuro del Matrimonio civil en España (Madrid, 1977).

Casanova Aguilar, Aproximación a la Constitución nonnata de 1856. Presentación general y primera publicación del texto integro (Murcia, 1995).

Castán VázQuez, El Código civil de Andrés Bello, factor de unidad, en Andrés Bello y el Derecho Latinoamericano, Congreso Internacional (Roma, 1981).

CASTÁN VÁzQUEZ, El proyecto de Código civil de 1851 y su influencia en las codificaciones iberoamericanas, en Anales de la Real Academia de Jurisprudencia y Legislación, número especial dedicado al Centenario del Código civil (Madrid, 1988).

Castán VázQuez, Humanismo y Derecho en Andrés Bello, en Anuario de la Facultad de Ciencias Jurídicas y Politicas de la Universidad de los Andes (Mérida, 1983-1984).

CASTÁn VÁzQuez, La influencia de García Goyena en las codificaciones americanas, en Homenaje al Profesor Roca Juan (Murcia, 1983).

Clavero, B., Evolución histórica del Constitucionalismo español (Madrid, 1984).

Clavero, B., La gran dificultad. Frustración de una ciencia del Derecho en la España del siglo XIX, en Ius Commune, 12 (1984).

Clavero, B., La idea de Código en la Ilustración jurídica, en Historia, Instituciones, Documentos, 6 (Sevilla, 1979).

Clavero, B., Materiales primeros para una historia constitucional de España, en AHDE., 59 (1989).

Clavero, El Código y el fuero (Madrid, 1982).

Comanducci, P., La costituzionalizzazione americana, un capitolo nella storia della 
cultura giuridica europea, en Materiali per una Storia della Cultura Giuridica, 17 (1987).

Crespo de Miguel, El matrimonio en los dictámenes oficiales sobre el Proyecto de Código civil español de 1851, en RGLJ. (1987).

D'Ors, A. - Bonet Correa, En el Centenario del Proyecto Isabelino de Código civil, en Información jurídica, 96 (1951).

D'ORs, A., Los derechos civiles regionales en la España moderna, en La formazione storica del Diritto moderno in Europa (Florencia, 1977).

de Castro, F., Derecho civil de España (Madrid, 1955), I.

de Esteban, J. - GonzÁlez-Trevijano, P. J., Curso de Derecho Constitucional español (Madrid, 1994).

De Los Mozos, Algunos aspectos de la influencia hispánica en el Código civil de Andrés Bello, en RGLJ. (1978).

DONEZAR, J. M., La constitución de 1869 y la revolución burguesa (Madrid, 1985).

Durán i Bas, Estudios Políticos y Económicos (Barcelona, 1856).

Escudero, J. A., Curso de Historia del Derecho. Fuentes e instituciones politico-administrativas (6a edición, 1990).

Figueras Pamies, La escuela juridica catalana frente a la codificación del Derecho español, Durán i Bas, su pensamiento jurídico-filosófico (Barcelona, 1987).

García Canales, Reforma de la Constitución de 1876, en Revista de Derecho Político, 8 (1981).

GarCía Goyena, Concordancia, motivos y comentarios del Código civil español (Madrid, 1852), III.

Gil Cremades, El reformismo español. Krausismo, escuela histórica, neotomismo (Barcelona, 1969).

Gil Cremades, El reformismo español. Krausismo, escuela histórica, neotomismo (Barcelona, 1969).

Gómez Arboleya, Estudios de teoría de la sociedad y del Estado (Madrid, 1962).

GOMEZ DE LA SERNA, Estado de la codificación al terminar el reinado de doña Isabel II, en $R G L J ., 39$ (1871).

Gómez Mampaso, Alonso Martínez y la Codificación Civil, Anales de la Real Academia de Jurisprudencia y Legislación, 19 (1988).

GonzÁlez Rodríguez, La forma de gobierno en el debate constituyente de 1869, en Revista de Derecho Político, 55-56 (2002).

GonzÁlez Vicen, La Escuela Histórica del Derecho, en Anales de la Cátedra Francisco Suárez, 18-19 (1978-79).

GONZÁlEZ-Ares, J. A., Introducción al estudio del constitucionalismo español. 1808-1975 (4a edición, Santiago de Compostela, 2003).

GonZÁlez-Ares, La Constitución moderada de 1845, notas y comentarios en el ciento cincuenta aniversario de su promulgación, en Revista del Colegio de Abogados de Ourense, 21 (1995).

Groizard, De la Codificación en España, en RGLJ., 21 (1862).

LACRUZ Berdejo, Las Concordancias de García Goyena y su valor para la interpretación del Código civil (Zaragoza de 1974) = RCDI., 50 (1974).

Lasso Gaite, Crónica de la Codificación española, IV: Codificación civil (Génesis e historia del Código) (Madrid, 1979).

MALUQUer De MOTES, La codificación civil en España, sintesis de un proceso, en RDP. (1981). 
Martínez Alcubilla, Boletín jurídico-administrativo, apéndice al Diccionario de la Administración española peninsular y ultramarina. Anuario de 1880 (Madrid, 1880).

Martínez Marina, Juicio crítico de la Novísima recopilación (Madrid, 1820).

Martiré, E., La importancia institucional de la Constitución de Bayona en el constitucionalismo hispanoamericano, en Historia Constitucional (revista electrónica), 9 (2008).

MelÉndez Valdés, Discurso de instalación y apertura de la Real Audiencia de Extremadura, en Discursos forenses (edición de M. J. Quintana, Madrid, 1821).

Mirete Navarro., M. Alonso Martínez y la polémica sobre la codificación en España, en Anales de la Universidad de Murcia. Derecho, 33 (1974-75) 1-2.

Palma y Luján, Congreso de Jurisconsultos, en RGLJ., 23 (1863).

Pérez Serrano, Constitucionalismo y Codificación, en Revista General de Legislación y Jurisprudencia (Madrid, 1953).

Pérez-Prendes, Continuidad y discontinuidad de la Constitución de 1876, en Revista de Derecho Político, 8 (1981).

Peset ReIG, Análisis y concordancia del proyecto del Código civil de 1821, Anuario de Derecho Civil, 28 (1975).

Piano-Mortari, s. v. Codice. Premessa storica, en ED., VII.

Puig Ferriol, El denominado problema foral desde la perspectiva de un Centenario, en Centenario del Código civil (Madrid, 1990), I.

Roca Trías, El Código civil y los derecho nacionales, en especial el Derecho civil catalán, en RJC., 3 (1997).

Roca Trías, La Codificación y el Derecho foral, en RDP. (1978).

Rodríguez EnNes, Florencio García Goyena y la codificación iberoamericana, en AHDE., 76 (2006).

Rodríguez Ennes, Historia do Dereito de Galicia (Vigo, 2000).

Rodríguez EnNes, Proceso histórico de formación del Derecho civil de Galicia, en Dereito. Revista Xurídica da Universidade de Santiago de Compostela, 5 (1996).

RoldÁn Berdejo, La Ley del Matrimonio civil del 1870. Historia de una ley olvidada (Granada, 1980).

Salvador Coderch, El Proyecto de Código de derecho civil de 1851 y el Derecho civil catalán, en RJC. (1980/1981), pp. 49 ss.; y (1982), pp. 313 ss.

SÁNCHEZ Ferriz, La Restauración y su constitución politica (Valencia, 1984).

SÁnCHEz RomÁn, Estudios de Derecho Civil. Historia General de la Legislación española (Granada 1880).

Sevilla Andrés, Historia política de España (1800-1973) (Madrid, 1974).

SOlÉ TurÁ, J. - AJA, E., Constituciones y periodos constituyentes en España (15ª edición, Madrid, 1990).

TARELlo, G., La ideologie della codificazione. Del particolarismo giuridico alla codificazione napoleónica (Genova, 1969).

TARello, G., Storia della cultura giuridica moderna, I: Assolutismo e codificazione del diritto (Bolonia, 1976).

Thibaut - Savigny, La codificación (trad. esp. Díaz García, Madrid, 1970).

Thibaut, A.F.J., Sobre la necesidad de un Derecho civil general para Alemania (Heidelberg, 1814).

Tomás Villarroya, El sistema político del Estatuto Real (Madrid, 1968). 
Tomás Villarroya, Las reformas de la Constitución de 1812 en 1836, en Revista del Instituto de Ciencias Sociales, 4 (1964).

TOMÁs y Valiente, Códigos y Constituciones (1808-1978) (Madrid, 1989).

Tomás y VALIENTE, Manual de Historia del Derecho Español (Madrid, 1983).

Tomás y Valiente, Notas para una nueva historia del constitucionalismo español, en Sistema, 17-18 (1977).

Tomás y Valiente, Obras completas (Madrid, 1997).

TORres del Moral, Constitucionalismo histórico español (Madrid, 1986).

Vallejo, J., Orden, libertad, justicia. Figuración constitucional republicana (1873), en AHDE., 57 (1997).

Vallet de Goytisolo, La polémica de la Codificación, la Escuela Filosófica y la Escuela Histórica, en Anales de la Real Academia de Legislación y Jurisprudencia, 19 (1988).

Varela Suanzes-Carpegna, La constitución española de 1837, una Constitución transaccional, en Revista de Derecho Politico, 20 (1983-1984).

Varela Suanzes-Carpegna, La monarquía imposible, la Constitución de Cádiz durante el trienio, en AHDE., 66 (1996).

Von Savigny, F.K., De la vocación de nuestra época para la legislación y la ciencia del derecho (Heidelberg, 1814, trad. al español PosADA, A., Buenos Aires, 1977). 